\title{
ECONOMIC EFFICIENCY AND EFFECTIVENESS IN DECISION MAKING
}

\author{
KurtuhuZ, A. M.; RAdu, D. L.; Anghel, A.; \\ ZAhiU, C. \& DUMiTRICA, M. A.
}

Abstract: The complexity and dynamism of social-economic activities, due to contemporary technical scientific revolution, deep economic transformation, social and political, which is currently running, requires a new vision effectively dealt with multi-criteria and multi-caused. Discounted in making investment decisions, with detailed analysis of efficiency indicators (during static and dynamic payback, updated economic return on investment, internal rate of return on investment, the relationship between income and costs) reflects the statement - evaluating an investment mainly involves the calculation and analysis of economic efficiency, which is a causal relationship between effort put into action and registered practical effect as a result of this effort.

Key words: management, decision making, human factors, efficiency
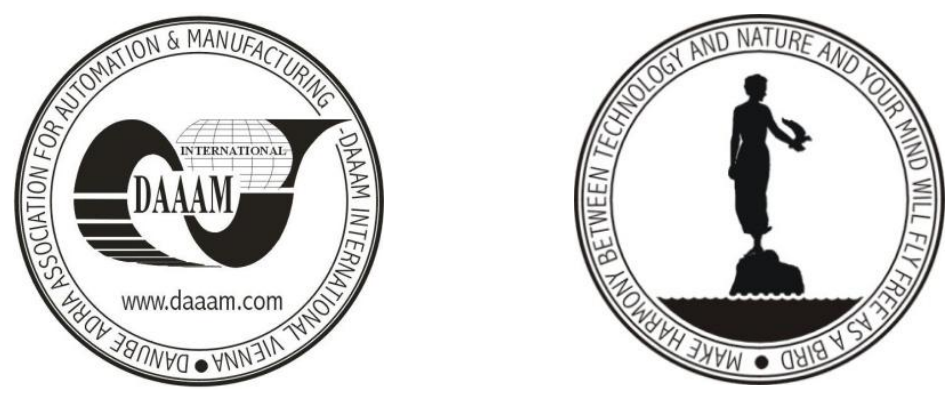

Authors' data: As.Univ.Dr.Ec. Kurtuhuz, A[ndreea] M[aria]; As.Univ.Drd. Radu, D[aniela] L[iana]; Lect.Univ.Dr. Anghel, A[lina]; As.Univ.Drd. Zahiu, C[amelia] E[lena] \&As.Univ.Drd. Dumitrica, M[ihaela] A[ndreia]; University of Valahia, Bd. Carol I,No.2,130024,Targoviste,Dambovita,Romania; andreea.kurtuhuz@yahoo.com.

This Publication has to be referred as: Kurtuhuz, $\mathrm{A}$ [ndreea] M[aria]; Radu, D[aniela] L[iana]; Anghel, A[lina]; Zahiu, C[amelia] E[lena] \& Dumitrica, M[ihaela] A[ndreia] (2013) Economic Efficiency and Effectiveness in Decision Making, Chapter 33 in DAAAM International Scientific Book 2013, pp. 609-618, B. Katalinic \& Z. Tekic (Eds.), Published by DAAAM International, ISBN 978-3-901509-94-0, ISSN 1726-9687, Vienna, Austria

DOI: 10.2507/daaam.scibook.2013.33 
Kurtuhuz, A. M.; Radu, D. L.; Anghel, A.; Zahiu, C. \& Dumitrica, M. A.: Eco...

\section{Introduction}

An analysis of the decision-making system shows a very high proportion of shortterm decisions, which lead to decisions with immediate effect often at the expense of medium and long -term decisions that are totally neglected. In fact such an approach on long-term has adverse effects, increasing the risk coefficient. Romania's public sector human factor is one of the most neglected resources and the consequences of this situation lead to effects that are not difficult to deduce. The human factor is a key element of business and public sector performance. Moreover, constitute essential elements of size and especially the quality of public sector activity. So you can not mention the effectiveness of public institutions in general without regard, in addition to economic efficiency and directly quantifiable aspects, and a number of imponderables directly, but have multiple effects on the performance of the public sector. Among them an important place, as is natural, civil servants work efficiency. The efficient use of staff's work efficiency depends on very quality and efficiency of public administration.

\section{Economic Efficiency-a main Element in Decision Making}

The concept of "economic efficiency" is encountered in the literature and in practice in two ways:

1. Performance - particularly good results - of an activity;

2. Maximum effect of an activity in relation to allocate resources or supplies.

But most of the specialists, addressing the "efficiency" have regarded to the private sector and little or not at all on the public. An explanation of this could be due to the truth that the government aims through its activities low profitability but high degree of satisfaction of citizens. Given that, referring to the private sector, many economists have defined special economic efficiency; it is absolutely natural to be considered for the analysis of institutions or authorities of central and local government and other public sector institutions.

In order to address the work in the public sector from the perspective of the concept of efficiency is necessary for efficiency to be understood and considered as due to the influence of economic factors and as a consequence of the influence of political, cultural, legal and especially the human factor because in fact "human resources are the underlying success or failure".

This concept was first used in public administration rational approach proposed by L. Gulick and L. Urwick. Public managers must consider the fact that if efforts can be sized strictly, particularly social ones, are difficult to determine and cannot be laid entirely. This is because the government operates in a social setting subject to multiple influences.

Most often these indirect unpredictable social effects have major implications in the public sector. In terms of forms of expression can be said that the efficiency can be quantified - particularly the economic - and quantifiable - social effects. Public managers should take account of both, but the fact that they may have in addition to the present size and size perspective, because a considerable part of the results 
obtained over a period of time. Unfortunately, most often, the efficiency perspective propagated - is ignored.

In other words, efficiency of public administration is determined by:

- The quality of administrative act;

- Skills, ability to work and proper execution of tasks;

- Local authorities' ability to perform tasks in a timely manner.

The issue of human resources in the public sector has multiple aspects of social and human, political, legal and technical. The issues arise in relation to the training of personnel of public institutions, problems with recruitment and assignment agreement, appreciation and promotion in various positions in general management personnel issues. There are also issues concerning the behavior of civil servants in their relations with citizens, issues related to interpersonal relationships within the public or staff regarding relations between the public sector and society.

All these aspects related to public administration staff not only be addressed but strictly legal point of view because they would lead to an incomplete knowledge of the realities of administration, because there are aspects of the work of civil servants who do not have legal regulation but have very important role to ensure the effectiveness of the public and achieve its social mission.

\section{Effectiveness-The Impact of Decision Making}

Many foreign experts believe that there can be no effective efficiency because "it is more important to realize better what your goals - efficiency - to achieve better than anything - efficiency"(Drucker, P. 1954).

Also states that the relationship between effectiveness and efficiency is one of part-whole, directly influencing efficiency effectiveness, especially the staff, being an intrinsic element of its even. More can be said that the effectiveness is an attribute of human personality is the source of knowledge, reason civil servants, and the relationships between them.

Both intrinsic efficacy as staff efficiency and the latter are very important for the overall efficiency of the public sector. Because it's not possible to organize rational and effective functioning of the public sector unmanned also extremely efficient and effective. In other words, efficiency and its intrinsic element - effectiveness - are essential and indispensable features civil servant labor.

Lacking these features, every civil servant work in hand would adversely affect the overall activity of the institution and / or authority. Furthermore, it threatens the very fundamental objective of the public institution: the public interest. As a result, public managers need to focus on human resource performance; growth will obviously influence the financial and material resource efficiency and overall efficiency of public institutions and authorities.

Therefore the value of public sector institutions and authorities in a country lies in both material and financial means at its disposal, and especially in its human potential. As a result, the reform of public administration should pay more attention to the human factor, which alone can make a more effective and viable in terms of economic and financial viability and management. 
Kurtuhuz, A. M.; Radu, D. L.; Anghel, A.; Zahiu, C. \& Dumitrica, M. A.: Eco...

Unfortunately many specialists in Reform believe that public administration reform is insufficient legal regulation of its activity, the main issues, without understanding that a legal framework is worth very little if not enough civil servants to exploit labor them. Many public managers in the public sector in our country do not understand that for administrative reform is not sufficient to complement and improve the legal framework, the creation of an appropriate institutional framework and even the development of programs related to recruitment, career plan, specialized training, and standards and control of the performance of civil servants. It takes longer, namely: a new perspective on the concept of civil servants and their role in the administrative system, a new approach to their work through the concepts of efficiency and effectiveness, as they are essential elements of success changes.

Highlighting interdependencies, multiple and complex, the management and efficiency aims at facilitating the efforts geared towards modernizing and increasing the efficiency of social, including the military, given the many changes occurring in contemporary society.

Influence of management on the efficiency can be analyzed both from a theoretical and pragmatic point of view. Fundamental premise from which we start the theoretical impact that management has on efficiency are:

a) effective management is the ultimate goal;

b) the management is a key to increase efficiency.

Influence of management theory on efficiency theory can highlight with a few essentials that we present below. First, the management helps with a systemic approach the efficiency through a system of indicators to assess its use and business practices. Management Sciences contributed to the design of indicators, differentiated according to the main objectives pursued by strategies and policies and their importance in programming-planning and control - Evaluation of the implementation.

In the same area of theoretical links between management and efficiency, it is necessary to design the management system and its major components, in order to be effective in terms of size, structure and interconnectedness (Kurtuhuz, A.M. et al, 2009). In the design of the management system should be considered macro and micro management principles, such as for example:

- Ensuring consistency among the driving range and management system parameters involved;

- Motivate all staff, both management and execution;

- Manageability.

Consideration of these principles provides favorable conditions for higher functionality of each subsystem. Thus, in designing organizational structures must take into account the requirements of principles, such as:

- The principle of supremacy objectives;

- Unit of decision and action;

- The principle of proximity management execution;

- Communication of economy; 
- The principle of a harmonized definition channels and functions to that track quality and high efficiency of organizational structures and thus high efficiency in areas driven.

In the design of information systems, in which the design and operation principles and subordination of managing the overall information system, information system flexibility to aimed at achieving direct odds Ratios, and the management information system and propagated in the driving subsystem.

Also, the design of methods and techniques of management and decisionmaking subsystem aims high efficiency goal and purpose of each component management, the management system as a whole.

Therefore, the design of the management system and its components are based on theoretical and methodological elements (principles, requirements, etc.) Focused on efficiency and with which the efficiency is projected to be achieved by each organizational link.

From a pragmatic point of view, the influence of management on efficiency is more obvious and has to be differentiated according to organizational levels referred to, respectively:

- The job within the company;

- Microeconomic system level;

- Macroeconomic and the social system.

Influence of management on the efficiency increases while the amplitude of complexity, functions and led the field size.

Highlighting elements impact management - cycle efficiency is based on information - decision - action - results, whose reduction enables continued increasing quality and efficiency driven activities. Cycle information - decision action closes, therefore, the two poles of his: the man and reality subject and object decision. Effectiveness of the decision is based equally on the accuracy with which it is perceived reality and choosing appropriate methods of action (Connoly, T. et al, 2000). Most synthetic said the decision is a conscious and voluntary action to convert the information, considering the circumstances that condition - logical and physical that transformation.

Reducing cycle information - decision - action - results depend largely on the degree of perfection of each of the subsystems management involved in running it, namely the informational, organizational and decision-making.

A rational informational subsystem provides accurate, concise and dynamic force transmitted to decision-making centers informational short circuits using advanced means and procedures.

The quality and effectiveness of the decisions depends to a large extent on the quality and quantity of information that is received by the makers, as the quality and effectiveness of decisions, the degree of substantiation depends on initial actions to implement them efficiently.

Regarding organizational subsystem, reduction of number of each hierarchical level, in the broader context of execution management approach represents a way of rationalizing the organizational, direct impact on efficiency. The existence of a 
Kurtuhuz, A. M.; Radu, D. L.; Anghel, A.; Zahiu, C. \& Dumitrica, M. A.: Eco...

rational number of levels with positive effects: reducing filtering and distortion of information and thus better information for managers, transmission executants of operative decisions, facilitating seamless fulfillment of the objectives contained in the strategy and policy. Increased economic efficiency of each product, the main objective of this stage can be achieved only if the whole decision process is conducted scientifically resorting to appropriate methods underlying the decision alternatives and evaluating their consequences.

An important role in the foundation of decision alternatives and their consequences evaluation methods and techniques they have used the decider. In the literature it is considered that there are two groups of procedures (methods) for solving practical decision problems, namely: the traditional and scientific methods (Turban, E. et al, 2005). The traditional is characterized by a large number of ways of developing decisional variants, but without having a general methodology based on certain principles or standards of work, which works to regulate succession, ways to assess the consequences of the choice of the solution optimal. Calling either of the methods is almost a question that depends on the quality decider. Traditional methods used are almost exclusively based on experience, intuition training, and so on, which occurs spontaneously at a decision maker to another, according to provide them with the mentioned qualities. The traditional and widely used now in the process of management and it is difficult to completely abandon them because they are useful in solving simple decision problems. Also, they are often a first approach to the complex decision problems that will be solved by appealing to modern computing methods and techniques.

Scientific processes differ from traditional ones in that each method or technique of decision making takes place after a rigorous methodology has a theoretical foundation and logical alternatives evaluation criteria are established scientifically that the decision maker can more easily appreciate optimal solution. Use in decision-making methods and techniques will ensure greater efficiency of the decisions taken and thus the overall activity of the economic entity. A method or another in decision making depends on the determination of anticipated situations of complex conditions that causes a particular variant of solving a goal to produce certain consequences. Management recognizes that a decision in a particular segment of the organization may not have a major effect on the segment, but also on other segments. Therefore, if possible, opt for total organization perspective. This approach is called system perspective or system approach.

The efficacy is the extent to which the proposed aims are reached. It is, therefore, the results or outputs of the system. Effectiveness is identical to achievement. Efficacy is assessed efficacy measures (measures of achievement). Effectiveness is often confused with efficiency. The effectiveness of the extent relates if a goal has been achieved; efficiency indicates how well resources are used. Efficacy not necessarily implies efficiency. A system can be effective but inefficient forces, if they achieve their goal with huge expenses. On the other hand, a system can be effective, but ineffective (not achieve its purpose).

Management aims to improve management decisions. Ideally reach decisions that lead to the highest degree of productivity (optimal situation). For many management systems, especially those involving provision of services, assessing the effectiveness and efficiency is a major problem. The reason for the difficulty is due to 
the existence of several purposes, as well as indirect expenses and earnings. In recent years some methodologies have been introduced which are called cost effectiveness analysis cost -earnings, earnings - expenditure report and analysis systems that intend to evaluate the effectiveness and efficiency of such systems. Management decision making is greatly facilitated by the use of methods and techniques specific or universal decision, considering the situation to be resolved. Calling in a greater measure to decision trees and other probabilistic methods, the methods and techniques based on utility theory, methods and techniques of economic analysis was, significantly increases the degree of substantiation, and the applicability of the decisions taken.

Along with the above, management efficiency and economic influence through informal aspects, more related management subjects, are on different levels. Exercise in terms of efficiency, competence and responsibilities of managers assume their part, not only specialized knowledge and managerial, but also skills, abilities and qualities that facilitate desired results. Thus, managers - regardless of the hierarchical level - must adopt a behavior -oriented training incumbent employees in achieving organizational subdivision led in terms of efficiency. Also, to promote participatory management professional, managers must possess knowledge and skills to adapt to collective management decisions, have an ability to work with people, to know how to listen, to expose some stops precisely and concisely, and to express fairness in dealing with its employees.

In the literature, more frequently emphasizes the influence that a particular management style has on efficiency (Kueng, P., Krahn, A.J.W.,2004); detaching styles are really effective and ineffective.Interrelation between management and effectiveness must be addressed in two ways, namely from the effective management and vice versa. Therefore, we will obviously continue to influence the efficiency of the management, both in terms of theoretical and pragmatic.

The first area in which the impact is significant theory on management efficiency is the methods and techniques for measuring the efforts, the effects of which are used for:

- management objectives size and the resources allocated to achieve them; - substantiation of investments with major implications on all other areas of activity;

- decision making to achieve the objectives assumed;

- evaluation of implementation decisions.

The starting point in sizing objectives of socio - economic system, by its management, it is getting a certain level of efficiency, superior previous period and focuses on gross and net effects expressed by indicators such as production efficiency, cost, profit, productivity etc.

For sizing strategic and tactical objectives and resources required by their achievement appeals, namely effective methods and techniques such as:

- Methods of maximizing effects in resource data;

- Methods of minimizing efforts (expenses) at a given level of effectiveness;

General methods and techniques applicable in other domains such as: 
- Methods and techniques with static - mathematical basis used in the design objectives, modalities of implementation and resources involved (stochastic different methods, mathematical programming, mathematical operators);

- Methods and techniques of economic analysis, decision-making centers which provide information on the evolution of economic processes and phenomena in previous periods.

In terms of development decision making, particularly investment decisions (the area where the impact of efficiency on management theory is significant), the main problem that arises is that of choosing the best options in terms of a set of criteria and integration economic, social restrictive - the strategy relates to:

- ensuring increasing profitability;

- saving funds available;

- the limited resources ;

- the influence of the time factor;

- the return on investment;

- producing a useful effect longer period after the passage of the recovery period was.

Using these criteria requires different methods and techniques, both specific and taken from other disciplines, such as, for example:

- Methods and techniques of economic analysis (especially the factorial);

- Global utility method for choosing decision alternatives in terms of certainty (electric methods);

- Minimizing deviation method;

- Linear programming (simplex algorithm);

- Statistical methods that allow detection of trends in phenomena, an estimate of the period covered, etc.;

- Updating technique, which underlies a wide range of indications of efficiency, since the prediction phase, based on a recovery factor for dynamic vision.

In terms of decision making for achieving the objectives, resort to different methods and techniques such as:

- Mathematical methods and techniques to support: critical path method, static and dynamics mathematical programming;

- Static methods and techniques index method, adjustment methods, regression and correlation;

- Methods and techniques for determining the production capacity resource sharing activities, the production function.

In evaluating the results of applying the decision problem that arises is the equivalence of the time, effort and effects, taking into account the influence of time, approached double role, namely that important economic resource and influence on economic processes. Quantifying the influence of time on the efficiency has a positive impact on the accuracy obtained efforts and effects. In terms of pragmatic, effective management influences on multiple levels, if we consider that economic 
activity (both at micro and macro world economic) cycle operates, ensuring continuity of production processes. Any area as a system approach multidimensional, dynamic, represents an important prerequisite for obtaining high levels of efficiency and effectiveness size recorded over a period of time within it takes its toll on the management, present and future, by a variety of issues, such as:

- Capacity and resources of the management structure, which in turn makes:

- Upgrading technical and material base of the economic system involved (company, group of companies, etc.)

- Amount of financial resources available for meeting management system that their targets;

- Magnitude and system technologies introduction, organizational systems, information modules, new or improved products and services and so on;

- Culture exists within the system involved, the mentality of its staff and that relates to:

- The importance given to the efficiency of decision making;

- Criteria of efficiency and how to use them;

- Concrete pragmatic demands on that system efficiency.

In conclusion, treatment of all the problems facing organizations at macro, miso and micro, in terms of efficiency, to meet the proper social order, is a main way to prove the quality and effectiveness of organizational management.

\section{Conclusion}

Treatment characteristics of modern organizations are directly linked with the particularities and specificities of public sector management, understanding of this area is indispensable for the development of a coherent process of administrative reform. Management means a set of beliefs and practices developed in different organizations as a strategy to improve the performance (" do managers and management institutions to be performing " Drucker , 1974), in many cases it was considered that the way in which public organizations can be made to operate more efficiently is the type of management taking specific private sector this is based on the idea that a good manager means practices and qualities similar regardless of the type of organization they work. But even if the modern public is a much different model, the "classic" specific characteristics of public management remain present. Public administration has a clear political inner being influenced by multiple values and have to make choices regarding priorities of different groups of influence. Decisions are based largely on value judgments (rather realistic approach costbenefits) and assessment criteria are more difficult to define. On the other hand a very important test for public organization is the election; this makes public organizations to be accountable to the electorate in a manner unparalleled in the private sector if any government can become a matter of "public interest". As the research results that public organizations presents an interesting combination of law and management, containing both related components and the delivery of the product as it relates to the legal provisions, tensions between the two components are not very 
Kurtuhuz, A. M.; Radu, D. L.; Anghel, A.; Zahiu, C. \& Dumitrica, M. A.: Eco...

easy to reconcile and bureaucratic dysfunctions underlying many to whom administration seems to be more likely.

This research proved that public organizations are space interaction of two distinct types of rationality: the legal and the management (rationality and historical reasons related to administrative systems development - the continental (FrancoGerman) government focused on the perception of the state as an instrument of action and the Anglo-Saxon countries (UK and U.S.) preoccupied with the idea of organizing in the public sector. Conception refers essentially legal to a better understanding of the structure and functioning of public administration, in particular by reference to texts.

Object science administration is built on the basis of the legal type, he is defined by analogy with the administrative law, and not from his own reflection, and the subjects are conceived as forming the substance of the textbook as usual administratively (structure, action, control). The law is generally perceived as a privileged means of knowledge and understanding of administrative reality, and this belief has as a corollary certain hostility to type sociological approach neglects the weight of legal regulations and administrative life of civil behavior. And methods are marked by mark law: relating to a deductive method, which starts from the law and then to examine the conditions of application, they are reluctant to empirical research. Any effort made to address issues in a more concrete so not accompany a rupture models of reasoning and concepts of administrative law.

In order to improve the efficiency and the effectiveness of a decision, the managerial concept of any organization should lie along the traditional concerns of science organizations perceived as a science of effective management and sets a utility in its essential finality. It should define clearly the rules, regulations, moreover, precepts that enable organizations to achieve the objectives which they propose in terms of efficiency and effectiveness.

\section{References}

Connoly, T., Arkes, H., Hammond, K. (2000) Judgment and Decision Making. An Interdisciplinary Reader,(2nd. ed.) Cambridge University Press, pp.4-5

Drucker, P. ( 1954). The Practice of Management, Harper \& Row, New York

Gulick, L. H. (1936). Notes on the Theory of Organization. L. Gulick \& L. Urwick (Eds.), Papers on the Science of Administration (pp. 3-35). New York: Institute of Public Administration

Kueng P., Krahn A.J.W.(2004). Building a Process Performance Measurement System: some early experiences, Journal of Scientific\&Industrial Research

Kurtuhuz, A.; Vasilescu, I.; Badea, R. \& Popescu, A. (2009). Reform in the Year of Economic Crisis, Annals of DAAAM \& Proceedings of the $20^{\text {th }}$ International DAAAM Symposium, 25-28th November 2009, Vienna, Austria, ISSN 1726-9679, ISBN 978-3-901509-70-4, Katalinic, B. (Ed.), pp. 1919-1920, Published by DAAAM International, Vienna

Turban, E., Aronson, J. E.,Liang, T.P. (2005). Decision Support Systems and Intelligent Systems, 7th Edition, Pearson Prentice Hall, ISBN: 0-13-046106-7 